\title{
Stepping up infection control measures in ophthalmology during the novel coronavirus outbreak: an experience from Hong Kong
}

\author{
Tracy H. T. Lai ${ }^{1,2}$ (D) Emily W. H. Tang ${ }^{1,2} \cdot$ Sandy K. Y. Chau ${ }^{3} \cdot$ Kitty S. C. Fung ${ }^{4} \cdot K^{\prime}$ enneth K. W. Li ${ }^{1,2}$ (D)
}

Received: 21 February 2020 /Revised: 25 February 2020 / Accepted: 26 February 2020 / Published online: 3 March 2020

(C) Springer-Verlag GmbH Germany, part of Springer Nature 2020

\begin{abstract}
Purpose Coronavirus disease (COVID-19) has rapidly emerged as a global health threat. The purpose of this article is to share our local experience of stepping up infection control measures in ophthalmology to minimise COVID-19 infection of both healthcare workers and patients.

Methods Infection control measures implemented in our ophthalmology clinic are discussed. The measures are based on detailed risk assessment by both local ophthalmologists and infection control experts.

Results A three-level hierarchy of control measures was adopted. First, for administrative control, in order to lower patient attendance, text messages with an enquiry phone number were sent to patients to reschedule appointments or arrange drug refill. In order to minimise cross-infection of COVID-19, a triage system was set up to identify patients with fever, respiratory symptoms, acute conjunctivitis or recent travel to outbreak areas and to encourage these individuals to postpone their appointments for at least 14 days. Micro-aerosol generating procedures, such as noncontact tonometry and operations under general anaesthesia were avoided. Nasal endoscopy was avoided as it may provoke sneezing and cause generation of droplets. All elective clinical services were suspended. Infection control training was provided to all clinical staff. Second, for environmental control, to reduce droplet transmission of COVID-19, installation of protective shields on slit lamps, frequent disinfection of equipment, and provision of eye protection to staff were implemented. All staff were advised to measure their own body temperatures before work and promptly report any symptoms of upper respiratory tract infection, vomiting or diarrhoea. Third, universal masking, hand hygiene, and appropriate use of personal protective equipment (PPE) were promoted.

Conclusion We hope our initial experience in stepping up infection control measures for COVID-19 infection in ophthalmology can help ophthalmologists globally to prepare for the potential community outbreak or pandemic. In order to minimise transmission of COVID-19, ophthalmologists should work closely with local infection control teams to implement infection control measures that are appropriate for their own clinical settings.
\end{abstract}

Keywords Coronavirus $\cdot$ COVID-19 $\cdot$ Hong Kong $\cdot$ Infection control $\cdot$ Ophthalmology $\cdot$ SARS-CoV-2

Kenneth K. W. Li

kennethli@rcsed.ac.uk

1 Department of Ophthalmology, United Christian Hospital, 130 Hip Wo Street, Kwun Tong, Kowloon, Hong Kong SAR

2 Department of Ophthalmology, Tseung Kwan O Hospital, 2 Po Ning Path, Tseung Kwan O, Hong Kong SAR

3 Department of Pathology, Tseung Kwan O Hospital, 2 Po Ning Path, Tseung Kwan O, Hong Kong SAR

4 Department of Pathology, United Christian Hospital, 130 Hip Wo Street, Kwun Tong, Kowloon, Hong Kong SAR

\section{Introduction}

Coronavirus disease (COVID-19) has rapidly emerged as a global health threat. The name COVID-19, which stands for coronavirus disease 2019, was proposed by the World Health Organization (WHO) [1]. The virus was officially named as 'severe acute respiratory syndrome coronavirus 2' (SARS-CoV-2) [2]. The incubation period of COVID-19 falls within 2 to 14 days according to the Centers for Disease Control and Prevention (CDC) [3], although the incubation period could be up to 24 days in rare cases [4]. Symptoms of the infection include fever, cough, fatigue, myalgia, dyspnoea and diarrhoea. Computed 
tomography scans showed patchy shadows or ground glass opacities in the lungs. Complications include acute respiratory distress syndrome, arrhythmia and shock, and the mortality rate was $2.3 \%$ according to a large-scale retrospective study [5]. SARSCoV-2 is highly contagious and has evolved into a global health threat within weeks. As of 27 February 2020, there were 82,294 confirmed cases involving 47 countries [6]. There were 92 confirmed cases of COVID-19 in Hong Kong, including both imported and local cases [7]. This paper aims to share our local experience to help ophthalmologists globally to take necessary measures to minimise COVID-19 infection of both healthcare workers and patients.

\section{The risks of COVID-19 to ophthalmologists and patients}

According to the WHO, during previous coronavirus outbreaks such as SARS, human-to-human transmission occurred through droplets, contacts and fomites, suggesting that the mode of transmission of COVID-19 could be similar [8]. As of 14 February 2020, 1716 healthcare workers in China were infected with COVID-19 and six of them died [9]. One of them was Dr. Li Wenliang, an ophthalmologist at Wuhan Central Hospital. In early January, he contracted COVID-19 from an asymptomatic glaucoma patient and succumbed to the disease one month later [10]. There were anecdotal reports suggesting that individuals may be infected by patients with subclinical infection [11], either by droplets or by direct contact with secretions from infected cases followed by subsequent inoculation into mucous membranes. Anecdotal reports suggested that when no eye protection was worn, the virus could also possibly be transmitted by aerosol contact with conjunctiva and cause infection [12-14]. Hence the close proximity between ophthalmologists and patients during slit lamp examination and direct ophthalmoscopy may pose an infectious risk to ophthalmologists. Ophthalmologists may also be caught off guard as conjunctivitis, though uncommon, could be the first presenting symptom of COVID-19, before the appearance of other symptoms such as cough and fever $[12,13]$. The American Academy of Ophthalmology has issued an alert advising ophthalmologists to wear masks and eye protection when seeing conjunctivitis patients with respiratory symptoms and history of international travel [14]. Moreover, in 2003, the SARS coronavirus was isolated from SARS patients' tear samples [15] and thus, it is possible that the novel coronavirus may also be present in tears of COVID-19 patients.

Globally, we, as ophthalmologists, are facing an ageing population and thus, most ophthalmic clinics are extremely busy and crowded. Elderly patients also appear to be at increased risk of severe COVID-19 infection and mortality [5, 16]. Furthermore, since ophthalmic consultations often involve multiple investigations, including visual acuity, intraocular pressure measurement, pupillary dilatation and others, it is not uncommon that patients have prolonged stay in the clinic to complete the whole examination [17]. All these factors potentially increase the risk of cross-infection, between patients and between healthcare workers and patients, in outpatient clinics in ophthalmology than other clinical disciplines.

\section{Strategies to prevent transmission in ophthalmology outpatient clinics}

Since 25 January 2020, Hospital Authority, the public health service provider in Hong Kong, activated the Emergency Response Level in all public hospitals [18]. To prevent transmission of COVID-19 in the eye clinic, we adopted the following measures in our ophthalmic clinics at the United Christian Hospital and Tseung Kwan O Hospital in Hong Kong. The two hospitals serve the eastern region of Kowloon peninsula of the Hong Kong Special Administrative Region with a catchment population of over 1,155,000. Both hospitals have inpatient isolation facilities and are responsible for management of COVID19 infected cases within the region. The infection control measures implemented in ophthalmology were based on detailed risk assessment by both local ophthalmologists and infection control experts. They were based on a three-level hierarchy of control measures: (1) Administrative control, (2) Environmental control and (3) The use of personal protective equipment (PPE).

\section{Administrative control}

This was the first and most important level of the hierarchy which involved the largest number of people. It was intended primarily to reduce the risk of exposure of uninfected people to people who had COVID-19 disease. These control measures included the following activities:

\section{Lowering patient attendance and suspension of elective clinical services}

With a daily attendance of over 500 patients in our outpatient clinic, it is important to reduce the number of outpatient attendance to prevent cross-infection in this vulnerable group of patients, as it has been shown that even subclinical patients are capable of transmitting the virus [11]. Informing a large number of outpatients to reschedule their appointments is often challenging. We took advantage of short message service (SMS) to send information to patients via their electronic mobile devices, at least one week in advance before their scheduled appointments, providing them with an enquiry phone number so they could call to postpone their appointments and consider drug-refill if appropriate. Out of 1117 SMS sent out during the first week of February 2020, we had an encouraging response rate of $23.5 \%$ (262 responses). 
$24.6 \%$ of patient attendance was reduced as a result. Medical records would be screened by ophthalmologists and new appointments were sent out by post.

Non-urgent elective services and operations were suspended in order to reduce the risk of transmission due to people gathering, and to conserve resources such as inpatient beds, manpower and personal protective equipment to combat the outbreak of COVID-19. Such services included elective cataract operations, electrodiagnostic studies, and contact lens clinics etc. Emergency surgeries were maintained.

\section{Patient triage}

As the model of transmission is mainly by droplets, all personnel in the hospital were requested to put on face masks. Signage and broadcast advising respiratory hygiene and cough etiquette were set up. According to emerging studies, up to $98 \%$ of COVID-19 infected cases presented with fever [19]. It is therefore necessary to ensure that fever patients are identified before they enter the clinical area. A triage station was set up at the entrance of eye clinic. All patients and their accompanying persons were screened using infra-red thermometers. Fever patients were provided with health advice pamphlets and were advised to seek medical attention and reschedule their eye clinic appointments if their eye conditions were non-urgent. Those with urgent eye conditions and fever were seen by the on-call ophthalmologist either at the Accident and Emergency Department, inpatient isolation rooms or inpatient wards after admission.

For afebrile patients, questionnaires to screen for TOCC (Travel to affected areas during the incubation period, Occupation, Contact of a suspected or confirmed case, Cluster of cases) were administered by triage nurses (Fig. 1). Patients fulfilling the following criteria were also identified: (i) patients (or patients who have family members or accompanying persons) who travelled to outbreak areas within 14 days, (ii) patients with symptoms of upper respiratory tract infection, such as cough, and (iii) patients with acute conjunctivitis. If they fulfil any of the above criteria, their clinic appointments would be postponed for at least 14 days, which is current understanding of the incubation period of COVID-19 [3]. Any patient who fulfilled any of the above criteria but required urgent ophthalmic attention would be diverted to a separate waiting area and seen by a designated ophthalmologist in a special room. Dedicated equipment and instruments were used and not shared with the other consultation rooms. Figure 2 illustrates the patient triage workflow.

To prevent cross-infection, inpatient consultations from other specialties were seen in respective parent wards instead of the outpatient eye clinic.

\section{Coronavirus Disease 2019 Questionnaire}

\section{Questions on FTOCC (Fever, Travel, Occupation, Contact, Clustering)}

\begin{tabular}{|ll|ll|}
\hline 1. & $\begin{array}{l}\text { Do you have any fever or upper respiratory symptoms (e.g. } \\
\text { cough, sore throat or runny nose), or have been diagnosed } \\
\text { with pneumonia recently? } \\
\text { (If you answered "Yes," please go to question 1a. If you } \\
\text { answered "No," please go to question 2. }\end{array}$ & No $\square$ \\
\hline 1a. & $\begin{array}{l}\text { Do any of your family members or close contacts also suffer } \\
\text { from the same symptoms? }\end{array}$ & Yes $\square$ & No $\square$ \\
\hline 2. & $\begin{array}{l}\text { Have you travelled to outbreak areas of the coronavirus } \\
\text { disease in the past 14 days? }\end{array}$ & Yes $\square$ & No $\square$ \\
\hline 3. & Are you a healthcare worker, or work in a wet market? & Yes $\square$ & No $\square$ \\
\hline 4. & $\begin{array}{l}\text { Did you have any contact with patients confirmed with } \\
\text { coronavirus disease in the past } 14 \text { days? }\end{array}$ & Yes $\square$ & No $\square$ \\
\hline
\end{tabular}

\section{Question on conjunctivitis}

\begin{tabular}{|l|ll|}
\hline 5. Do you have conjunctivitis (pink eye)? & Yes $\square \quad$ No $\square$ \\
\hline
\end{tabular}

Fig. 1 Questionnaire on Fever, Travel, Occupation, Contact and Clustering (FTOCC) 


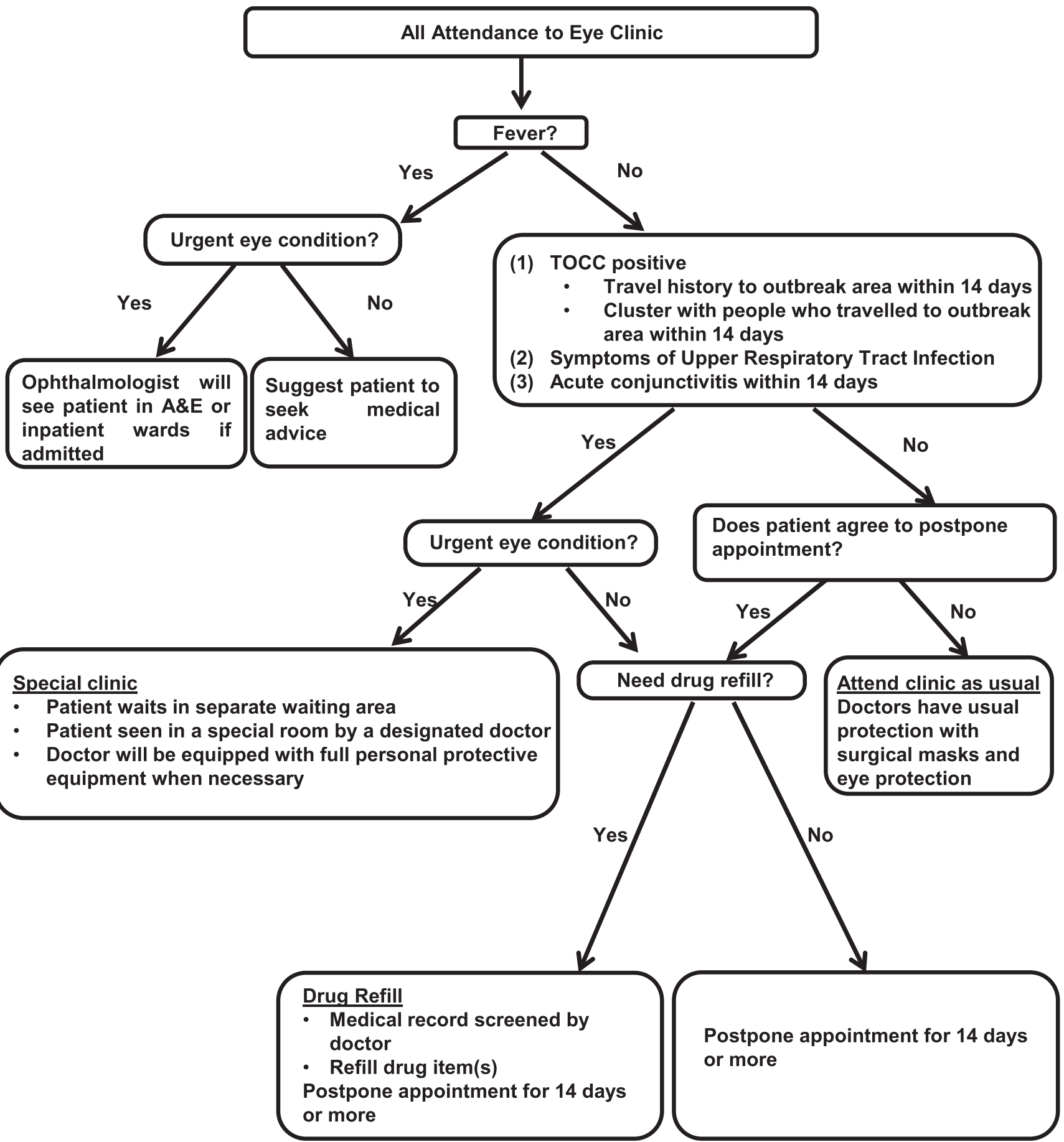

Fig. 2 Patient triage in the ophthalmology outpatient clinic. Abbreviations: A\&E - Accident and Emergency Department; TOCC - Travel, Occupation, Contact and Clustering

Reduction of aerosol and droplet generation in ophthalmology

As medical experts recently suggested that COVID-19 is capable of aerosol transmission [20], routine aerosol generating procedures in ophthalmic practice should be suspended.
Non-contact tonometry (NCT) is a potential source of microaerosol [21]. Using a camera and flash that were electrically coupled to a NCT machine, Britt et al. [21] studied the disruption of tear film when a pulse of pressurized air was blown towards the eyes. They reported tear film dehiscence and microaerosol formation. Therefore, it is prudent 
to suspend the use of non-contact tonometry in outbreak areas. Other ways of intraocular pressure measurement, such as iCare tonometry or Goldmann applanation tonometry should be used instead. With the use of disposable tips in tonometry, the risk of cross-infection should be minimised.

Ophthalmologists who performed endoscopic dacryocystorhinostomy often perform nasal endoscopy preoperatively and postoperatively. As nasal endoscopy may irritate the nasal mucosa and provoke sneezing, and often involves suction of nasal discharge, it poses an infectious risk to the operator and should be avoided as much as possible. If unavoidable, appropriate personal protection equipment should be utilised [22].

If ophthalmic surgery needs to be done, it should preferably be done under local anaesthesia and not general anaesthesia, as endotracheal intubation is of aerosol generating nature [22]. If emergency operation under general anaesthesia is inevitable (e.g. macula-on retinal detachment repair), ophthalmologists should work closely with anaesthetists and internal physicians to ensure COVID-19 rapid test is done for fever and TOCC positive cases before proceeding under general anaesthesia [23]. For patients who tested positive, patients who tested negative but were clinically suspicious, or in ultra-urgent cases when it was not feasible to wait for the test result, the operation would be performed in an isolation operating theatre and all staff would wear isolation gowns, N95 respirators and protective eyewear.

\section{Infection control training and staff monitoring}

All staff should undergo infection control training to familiarise themselves with the proper steps of hand hygiene and donning and doffing of personal protective equipment. All clinical staff were required to measure and report their own body temperatures before work, and report any symptoms such as fever, chills, myalgia, sore throat, runny nose, cough, vomiting, diarrhoea or pneumonia. Staff were encouraged to report their travel histories after returning from holidays.

\section{Environmental control}

The aim of environmental control was to prevent the spread and reduce the concentration of infectious droplet in ambient air. Air ventilation at the waiting areas was enhanced via opening of the fresh air dampers in the air handling equipment to achieve a higher fresh air rate with improved air dilution. Mobile high efficiency particulate air (HEPA) units were added to augment the total air change rates in waiting areas where necessary.

The close proximity between ophthalmologists and patients during slit lamp examination puts ophthalmologists at risk of infection, as droplets from a cough or sneeze can travel up to six feet [24]. To lower the risk of transmission via droplets, protective shields (made of plastic) were installed on slit lamps (Fig. 3). These shields acted as barriers to droplets and

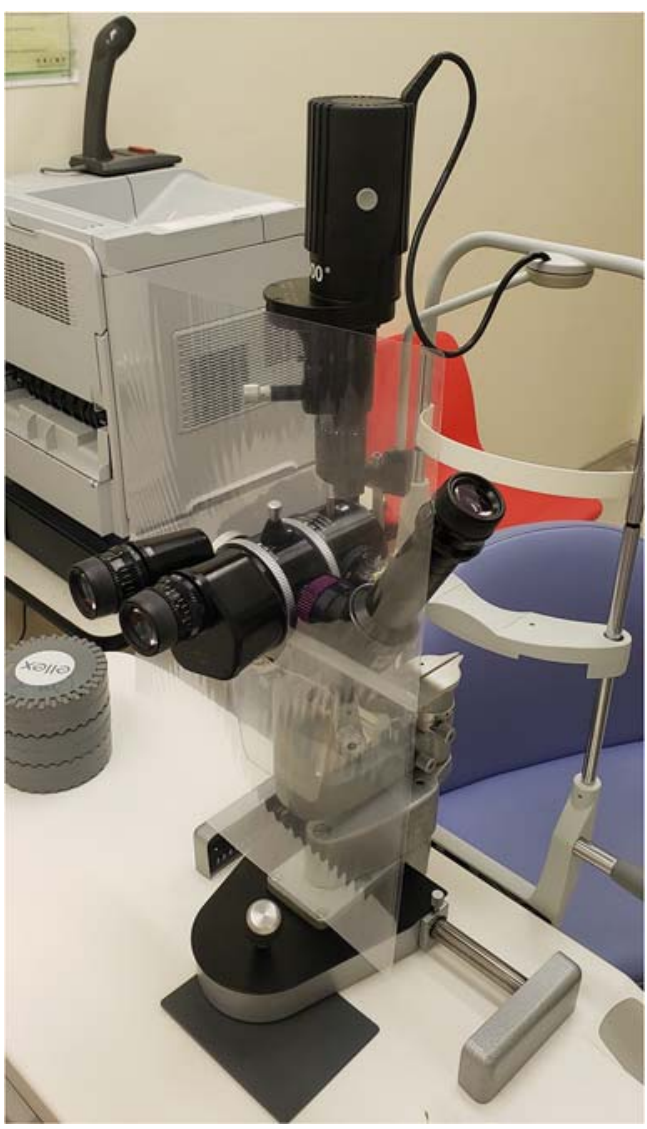

Fig. 3 Protective shield installed on a slit lamp

they were cleaned and disinfected after every clinic session, or if the shields were visibly soiled or contaminated. Equipment such as slit lamps and binocular indirect ophthalmoscopes, and environmental surfaces that were frequently touched by healthcare workers and patients (such as doorknobs, phones, and computer keyboards) were disinfected according to local disinfection guidelines.

To minimise gathering of staff for academic meetings, the use of video conference via personal mobile devices was helpful and encouraged. Appropriate distancing between diners in canteens should be adopted, for instance, staff were recommended to sit in one-way direction.

\section{Use of personal protective equipment (PPE)}

The first two control levels reduce the areas of exposure to SARS-CoV-2 but do not eliminate the risk in the areas where exposure could still occur (for example, isolation rooms housing COVID-19 patients, or treatment rooms in which aerosolgenerating procedures were performed on COVID-19 patients). The use of personal protective equipment in these situations could further reduce the risk of exposure of healthcare workers to infectious droplets expelled from a patient with infectious COVID-19 disease. 
Under the Emergency Response level in Hong Kong, universal masking in all hospitals and clinics was practiced. Eye protection equipment such as visors or protective eyewear were provided to all ophthalmologists and surgical masks were worn by both ophthalmologists and patients. Ophthalmologist attending higher risk patients at designated areas took extra precautions and wore full personal protective equipment including isolation gown, gloves, cap, eye protection, and surgical mask (or N95 respirator when necessary). Hand hygiene is particularly important and ophthalmologists should practise hand hygiene using the WHO formula alcohol hand rub or hand washing after every patient encounter. If gloves were worn, they were removed followed by hand hygiene between cases.

\section{Conclusion}

Hong Kong was hard hit by the SARS coronavirus in 2003, costing the lives of 299 Hong Kong people. A total of 405 healthcare workers were infected and eight of them succumbed to SARS $[25,26]$. We hope our initial experience in stepping up infection control measures for COVID-19 infection in ophthalmology can help ophthalmologists globally to prepare for the potential community outbreak or pandemic. Nevertheless, due to variations in outbreak severity and individual hospital settings in different localities, we suggest ophthalmologists to consult their local infection control experts for detailed risk assessment before deciding on the extent of infection control measures to be implemented in their own clinical settings. As the novel coronavirus infection is still in uprising trend, it is of paramount importance to remain vigilant and start taking necessary measures to prevent its transmission.

Acknowledgements The authors would like to dedicate this paper to all members of the Departments of Ophthalmology, Specialist Outpatient Departments, Infection Control Teams and Information Technology Departments of United Christian Hospital and Tseung Kwan O Hospital for their tremendous effort and contributions in combating COVID19. The authors thank Ms. Monica Lee, Department Operations Manager of Ophthalmology, for her excellent coordination.

\section{Compliance with ethical standards}

Conflict of interest All authors certify that they have no affiliations with or involvement in any organization or entity with any financial interest (such as honoraria; educational grants; participation in speakers' bureaus; membership, employment, consultancies, stock ownership, or other equity interest; and expert testimony or patent-licensing arrangements), or non-financial interest (such as personal or professional relationships, affiliations, knowledge or beliefs) in the subject matter or materials discussed in this manuscript.

Ethics approval This article does not contain any studies with human participants performed by any of the authors.
Informed consent Informed consent was not required as this article does not contain any studies with human participants performed by any of the authors.

\section{References}

1. WHO Director-General's remarks at the media briefing on 2019nCoV on 11 February 2020. (2020) World Health Organization. https://www.who.int/dg/speeches/detail/who-director-general-sremarks-at-the-media-briefing-on-2019-ncov-on-11-february2020. Accessed 18 Feb 2020

2. COVID-19. (2020) World Health Organization. https://www.ecdc. europa.eu/en/novel-coronavirus-china. Accessed 18 Feb 2020

3. Symptoms of Coronavirus Disease 2019. (2020) Centers for Disease Control and Prevention. https://www.cdc.gov/ coronavirus/2019-ncov/about/symptoms.html. Accessed 16 Feb 2020

4. Guan W-J, Ni Z-Y, Hu Y, Liang W-H, Ou C-Q, He J-X, Liu L, Shan H, Lei C-L, Hui DS, Du B, Li L-J, Zeng G, Yuen K-Y, Chen R-C, Tang C-L, Wang T, Chen P-Y, Xiang J, Li S-Y, Wang J-L, Liang ZJ, Peng Y-X, Wei L, Liu Y, Hu Y-H, Peng P, Wang J-M, Liu J-Y, Chen Z, Li G, Zheng Z-J, Qiu S-Q, Luo J, Ye C-J, Zhu S-Y, Zhong N-S (2020) Clinical characteristics of 2019 novel coronavirus infection in China. medRxiv:2020.2002.2006.20020974. https://doi. org/10.1101/2020.02.06.20020974

5. Team TNCPERE (2020) The epidemiological characteristics of an outbreak of 2019 novel coronavirus diseases (COVID-19). China CDC Weekly 2020

6. Coronavirus disease 2019 (COVID-19). Situation Report - 38. (2020) World Health Organization. https://www.who.int/docs/ default-source/coronaviruse/situation-reports/20200227-sitrep-38covid-19.pdf?sfvrsn=9f98940c 2. Accessed 28 Feb 2020

7. Latest Situation of Coronavirus Disease (COVID-19) in Hong Kong. (2020) Centre for Health Protection, Department of Health, Hong Kong Special Administrative Region. https://chp-dashboard. geodata.gov.hk/covid-19/en.html . Accessed 27 Feb 2020

8. Coronavirus disease 2019 Situation Report - 25. (2020) World Health Organization. https://www.who.int/docs/default-source/ coronaviruse/situation-reports/20200214-sitrep-25-covid-19.pdf? sfvrsn=61dda7d 2. Accessed 15 Feb 2020

9. WHO Director-General's remarks at the media briefing on COVID2019 outbreak on 14 February 2020. (2020) World Health Organization. https://www.who.int/dg/speeches/detail/whodirector-general-s-remarks-at-the-media-briefing-on-covid-2019outbreak-on-14-february-2020. Accessed 15 Feb 2020

10. Coronavirus kills Chinese whistleblower ophthalmologist. (2020) American Academy of Ophthalmology. https:/www.aao.org/ headline/coronavirus-kills-chinese-whistleblower-ophthalmol. Accessed 15 Feb 2020

11. Chang D, Xu H, Rebaza A, Sharma L, Dela Cruz CS (2020) Protecting health-care workers from subclinical coronavirus infection. Lancet Respir Med. https://doi.org/10.1016/S2213-2600(20) 30066-7

12. Zhou Y, Zeng Y, Tong Y, Chen C (2020) Ophthalmologic evidence against the interpersonal transmission of 2019 novel coronavirus through conjunctiva. medRxiv:2020.2002.2011.20021956. https:// doi.org/10.1101/2020.02.11.20021956

13. Lu CW, Liu XF, Jia ZF (2020) 2019-nCoV transmission through the ocular surface must not be ignored. Lancet (London, England). https://doi.org/10.1016/s0140-6736(20)30313-5

14. Alert: Important coronavirus context for ophthalmologists. (2020) American Academy of Ophthalmology. https://www.aao.org/ headline/alert-important-coronavirus-context. Accessed 18 Feb 2020 
15. Loon SC, Teoh SC, Oon LL, Se-Thoe SY, Ling AE, Leo YS, Leong $\mathrm{HN}$ (2004) The severe acute respiratory syndrome coronavirus in tears. Br J Ophthalmol 88(7):861-863. https://doi.org/10.1136/bjo. 2003.035931

16. Wang D, Hu B, Hu C, Zhu F, Liu X, Zhang J, Wang B, Xiang H, Cheng Z, Xiong Y, Zhao Y, Li Y, Wang X, Peng Z (2020) Clinical characteristics of 138 hospitalized patients with 2019 novel coronavirus-infected pneumonia in Wuhan, China. Jama. https:// doi.org/10.1001/jama.2020.1585

17. What Happens at an Eye Exam? WebMD. https://www.webmd. com/eye-health/what-to-expect-checkup-eye-exam-adults\#2. Accessed 16 Feb 2020

18. Hospital Authority activates Emergency Response Level. (2020) https://www.info.gov.hk/gia/general/202001/25/P2020012500689. htm. Accessed 15 Feb 2020

19. Huang C, Wang Y, Li X, Ren L, Zhao J, Hu Y, Zhang L, Fan G, Xu J, Gu X, Cheng Z, Yu T, Xia J, Wei Y, Wu W, Xie X, Yin W, Li H, Liu M, Xiao Y, Gao H, Guo L, Xie J, Wang G, Jiang R, Gao Z, Jin Q, Wang J, Cao B (2020) Clinical features of patients infected with 2019 novel coronavirus in Wuhan, China. Lancet (London, England). https://doi.org/10.1016/s0140-6736(20)30183-5

20. Shanghai officials reveal novel coronavirus transmission modes. (2020) https://www.chinadaily.com.cn/a/202002/08/ WS5e3e7d97a310128217275fc3.html. Accessed 15 Feb 2020
21. Britt JM, Clifton BC, Barnebey HS, Mills RP (1991) Microaerosol formation in noncontact 'air-puff' tonometry. Arch Ophthalmol (Chicago, Ill : 1960) 109(2):225-228. https://doi.org/10.1001/ archopht.1991.01080020071046

22. Tran K, Cimon K, Severn M, Pessoa-Silva CL, Conly J (2012) Aerosol generating procedures and risk of transmission of acute respiratory infections to healthcare workers: a systematic review. PLoS One 7(4):e35797. https://doi.org/10.1371/journal.pone. 0035797

23. CDC Tests for COVID-19. (2020) Centers for Disease Control and Prevention. https://www.cdc.gov/coronavirus/2019-ncov/about/ testing.html. Accessed 16 Feb 2020

24. How Flu Spreads. (2020) Centers for Disease Control and Prevention. https://www.cdc.gov/flu/about/disease/spread.htm. Accessed 15 Feb 2020

25. Leung GM, Ho LM, Lam TH, Hedley AJ (2009) Epidemiology of SARS in the 2003 Hong Kong epidemic. Hong Kong Med J = Xianggang yi xue za zhi 15(Suppl 9):12-16

26. Hung LS (2003) The SARS epidemic in Hong Kong: what lessons have we learned? J R Soc Med 96(8):374-378. https://doi.org/10. $1258 /$ jrsm.96.8.374

Publisher's note Springer Nature remains neutral with regard to jurisdictional claims in published maps and institutional affiliations. 